\title{
Comparison of Soil Water Retention Curves for sandy clay, obtained using different laboratory testing methods
}

\author{
Piotr Osinski ${ }^{1 a}$, David Toll ${ }^{2}$, Eugeniusz Koda ${ }^{1}$ \\ ${ }^{1}$ Department of Geotechnical Engineering, Faculty of Civil and Environmental Engineering, Warsaw University of Life Sciences, \\ Nowoursynowska Street 159, 02-776 Warsaw, Poland. \\ ${ }^{2}$ School of Engineering and Computing Sciences, Durham University, South Road, DH1 3LE Durham, UK
}

\begin{abstract}
The design of engineering structures is still a challenging task when considering unsaturated soil mechanics behaviour. The present paper focuses on analysing Soil Water Retention Curves (SWRC) for clayey soil samples collected from a purpose built experimental embankment. SWRC determination is crucial when analysing geotechnical parameters of the soil. During the measurements, soil samples were subjected to wetting and drying cycles using a stage procedure (where the process is carried out in stages to allow equalisation) and continuous processes. The methods used for obtaining the suction curves were high suction tensiometer, attached at the bottom of the sample, and pressure plates with suctions applied up to $800 \mathrm{kPa}$. The study compares laboratory methods on measuring suction for sandy clay samples. It proves that the wetting and drying history have an impact on the hydraulic behaviour of tested material. In order to give a wider picture of soil behaviour it also presents the outputs as a function of matric suction and volumetric and gravimetric water content, and degree of saturation.
\end{abstract}

\section{Introduction}

Unsaturated soil mechanics play a significant role when designing earth structures like railway and road embankments, dams, dykes or shallow foundations. They are commonly constructed in the vadose zone (Figure 1). Their mechanical properties are subjected to the hydraulic changes which are caused by the different climate events. Soil Water Retention Curves (SWRC) determination is crucial when analysing geotechnical parameters of the soil, especially when analysing rainfall triggered slope failures [1-3]. The present paper focuses on analysing SWRC for compacted clay soil samples, prepared at different moisture contents and subjected to wetting and drying cycles. The reason for applying hydraulic cycles was to reflect different climate scenarios [2]. As the soil suction has an impact on mechanical strength of the fill material for earth structures, it is crucial to determine and understand the hydraulic behaviour of the soil.

SWRC generally reflects soil behaviour for adsorption and desorption processes. It is usually presented as a relationship between water content (gravimetric or volumetric), or degree of saturation against soil suction which can be expressed in $\mathrm{kPa}$. There are three main stages that can be distinguished when obtaining the SWRC. At the beginning of the drying process the soil may be close to full saturation. As drying proceeds, causing an increase in suction, air starts to enter the pores of the soil defining the air entry value of the soil. Beyond the air entry value, the stage of desorption

\footnotetext{
${ }^{\mathrm{a}}$ Corresponding author: piotr_osinski@interia.pl
}

process is the transition zone, where most of the desaturation takes place. This is followed by residual suction, what means that the only water present in the soil is that which is closely bound to soil particles [2, 4]. All these stages can be observed for all type of soils, however shapes of SWRC and suctions values could vary significantly. This is due to the fact that soil suction is also influenced by other factors such as void ratio, soil structure, stress history and stress state [5-7].

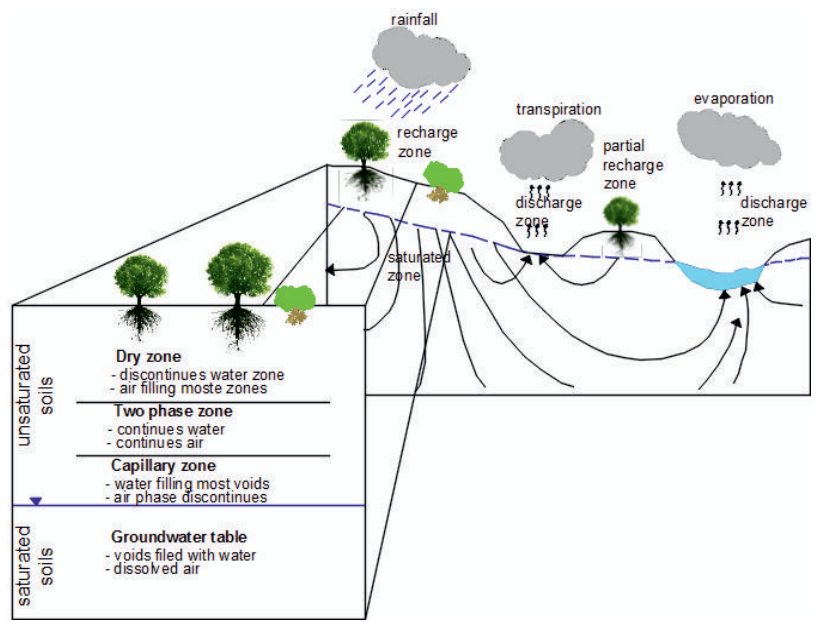

Figure 1. Unsaturated soil zone location.

Another crucial feature of a SWRC is its hysteretic character. That means that suction curves for wetting and drying are not reversible. That is why analysing hydraulic 
behaviour and its influence on the geotechnical parameters is so challenging [8-11].

The present paper focuses on determining and evaluating SWRC for sandy clay samples using different testing methods and approaches. The methods used for obtaining the suction curves were the tensiometer, attached at the bottom of the sample, and the axis translation technique. For the first method a high capacity suction probe was used, for the latter one, the pressure plate method. There were also different approaches applied. Compacted samples were subjected to stage drying and wetting cycles, but also the suctions were directly measured for continuous repeated wetting and drying paths that provides the best option in terms of evaluating the hysteresis of different hydraulic paths.

\section{Materials and methods}

\subsection{Soil sample preparation}

The soil material used for the study was classified as sandy clay. The grain size distribution of the material was obtained by using sieving method. The material was collected from a purpose built experimental embankment located near Newcastle, UK [12]. First the physical parameters of the soil were tested in the laboratory and then specimens were prepared. All the physical tests were conducted by using methods specified in British Standards [13]. The results for physical parameters testing are provided in Table 1.

Table 1. Physical parameters of the tested material.

\begin{tabular}{|c|c|c|c|c|c|c|}
\hline \multirow{2}{*}{$\begin{array}{c}\text { Soil } \\
\text { type }\end{array}$} & \multicolumn{2}{|c|}{$\begin{array}{c}\text { Light } \\
\text { compaction } \\
\text { Proctor test }\end{array}$} & \multicolumn{3}{|c|}{ Atterberg limits } & \multirow{2}{*}{$\begin{array}{c}\rho_{\mathrm{s}} \\
{\left[\mathrm{g} / \mathrm{cm}^{3}\right]}\end{array}$} \\
\cline { 2 - 5 } & $\begin{array}{c}\mathrm{W}_{\mathrm{opt}} \\
{[\%]}\end{array}$ & $\begin{array}{c}\rho_{\mathrm{dmax}} \\
{\left[\mathrm{g} / \mathrm{cm}^{3}\right]}\end{array}$ & $\begin{array}{c}\mathrm{LL} \\
{[\%]}\end{array}$ & $\begin{array}{c}\mathrm{PL} \\
{[\%]}\end{array}$ & $\begin{array}{c}\text { PI } \\
{[\%]}\end{array}$ & \\
\hline $\begin{array}{c}\text { Sandy } \\
\text { clay }\end{array}$ & 15 & 1.73 & 41.5 & 20.1 & 21.4 & 2.60 \\
\hline
\end{tabular}

The samples used for the SWRC determination were prepared "as compacted" at $25 \%$ of water content. First the soil was oven dried and sieved to achieve a density that was as homogenous as possible. Then portions of soil were placed into the plastic bags and water was added. The prepared soil was left for $24 \mathrm{~h}$ to allow even moisture distribution through the soil.

The samples were reconstituted in a $100 \mathrm{~mm}$ diameter by $200 \mathrm{~mm}$ high split mould, and compacted using light compaction Proctor tests (Figure 2). The core of the soil was extruded and trimmed to the required dimensions. After trimming each sample, specimens for water content measurements were also collected to ensure the water content was uniform throughout the soil sample profile. There were two sizes of samples prepared for the purpose of the study. The first one, used for the stage drying and wetting was $50 \mathrm{~mm}$ diameter by $20 \mathrm{~mm}$ high and the other was $75 \mathrm{~mm}$ diameter by $20 \mathrm{~mm}$ high. The latter size was used for samples subjected to continuous hydraulic path determination and for the pressure plate method. Trimming to the desire sizes was achieved by pressing stainless still rings into the soil sample core.

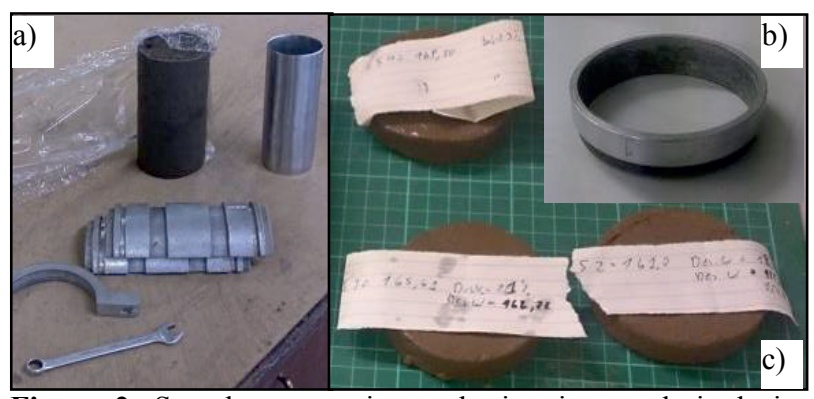

Figure 2. Sample preparation and trimming to desired size: a) sample core extruded after Proctor test; b) stainless still ring; c) soil specimens, size of $20 / 75 \mathrm{~mm}$.

\subsection{Pressure plate method for SWRC determination}

The pressure plate method uses the axis translation technique. It allows controlling and maintaining the desired value of suction rather than measuring it. The system consists of a sealed chamber where a High Air Entry Value Porous Disc (HAEVPD) is placed. The soil suction is created by imposing an air pressure on samples placed on the HAEVPD, and by changing the water pressure of tested samples. The matric suction for the axis translation technique is expressed as $\left(\mathrm{u}_{\mathrm{a}}-\mathrm{u}_{\mathrm{w}}\right)$ which is a difference between the imposed air pressure $\left(u_{a}\right)$ and the water pressure $\left(u_{w}\right)$ of the soil sample, both controlled during the test. The amount of suction that could be generated by using the pressure plate system depends on the Air Entry Value of the ceramic disc used for the test. Usually this value ranges from 500 to $1500 \mathrm{kPa}$.

The system that was used for the purpose of this study was modified (Figure 3 ). Instead of using a single porous ceramic disc, there were three HAEVPD that allowed independent measurement for each soil sample. Each disc of $1500 \mathrm{kPa}$ air entry value was connected to a different water volume measurement.

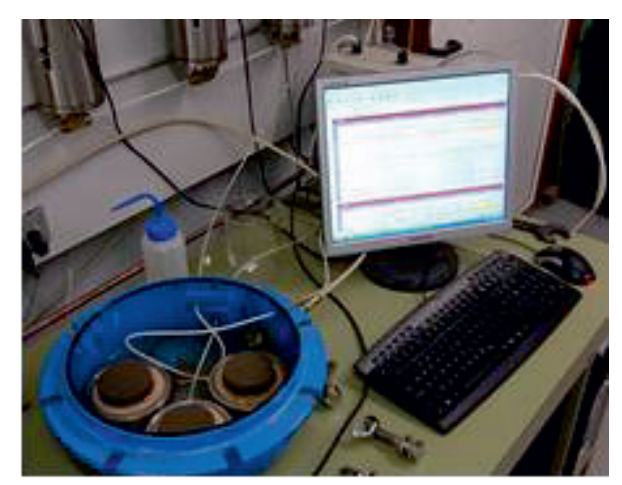

Figure 3. Pressure plate system, with three independent $1500 \mathrm{kPa}$ HAEV ceramic disks connected to water volume controllers.

The air pressure in the chamber was applied in stages, and the water pressures where adjusted accordingly, to achieve the desired value of suction. Then the system was left to equalise; the next stage was commenced when no volume change of the water coming 
out of each specimen was recorded. The stages of imposing air pressure were repeated, the volume changes of water were measured thus the SWRC could be plotted. Measurements of sample volume were obtained using a Vernier calliper and the mass change was taken by weighing manually after equalisation at each suction level (assuring that no soil mass was left on the porous plate). The whole system was connected to the data acquisition system which was supported by TRIAX software developed at Durham University [14].

\subsection{High suction probe for SWRC determination}

\subsubsection{Description of high suction probe used in the study}

The tensiometer used for the study was the one designed in Durham University by Lourenço et al. [15]. Since the first development of a high suction probe by Ridley and Burland in 1993 [16] there have been a number of improvements and modifications applied. The main characteristic that distinguishes pore pressure transducers from each other is the air entry value of the ceramic disc and the form of construction. Figure 4 shows the instrument used for the study consisting of (from the top): $1500 \mathrm{kPa}$ porous stone, small water reservoir, spacer, ceramic transducer and electrical connection. The entire components are enclosed in a stainless steel casing (Figure 4). Another successful design was also reported by Tarantino and Mongiovì [17], however this used a strain gauged diaphragm instead of a ceramic transducer.

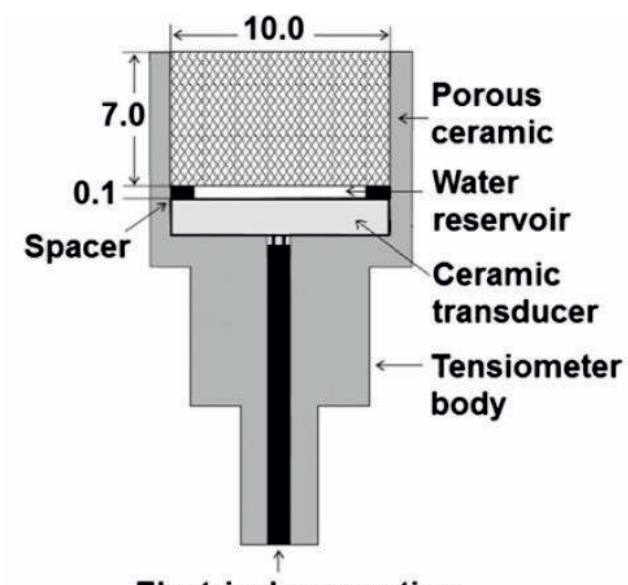

\section{Electrical connection}

Figure 4. Design of tensiometer used in the study [18].

The great advantage of the high suction probe is its almost immediate response when measuring the suction. Prevention of cavitation is achieved through using a small water reservoir. The maximum negative pore water pressure measured with the use of the tensiometer developed in Durham University was $2.1 \mathrm{MPa}[4,15]$.

\subsubsection{Stage drying and wetting approach}

The first approach used for determination of SWRC using the high suction probe was a stage drying and wetting procedure. The samples were prepared as compacted, by using light Proctor tests at the initial water content of $25 \%$. The samples were trimmed to the desired dimensions of $20 \mathrm{~mm}$ height and $50 \mathrm{~mm}$ diameter. The sample was then placed on a pedestal with the tensiometer attached at the bottom of the supporting plate and sealed with an O-ring [4]. To ensure permanent contact with the device the sample was gently pressed down. Then the sample was covered by a sealed container and left to reach equilibrium of suction reading. After recording the suction value the sample was removed from the pedestal, and the measurements such as weight and dimension changes were taken manually. In the next stage, depending on the hydraulic path determination, the sample was dried (open to atmosphere) or wetted (by using a syringe to add water) to reach the new desired water content. Then the sample was wrapped in cling film, closed in an air tight container and left for $24 \mathrm{~h}$ to reach water distribution equilibrium, then again the suction was measured. The procedure was repeated for a number of water contents from $25 \%$ to $16 \%$. The suction measurements were taken in stages.

\subsubsection{Continuous drying and wetting approach}

In contrast to the stage approach, for the continuous method all the measurements such as mass, volume and suction changes are taken continuously. All the readings are digitally recorded by the data acquisition system supplied with TRIAX software [14]. The major component of the system is a PCV framework with high suction probe fixed at the bottom of the supporting plate, and six local small strain transducers (LVDT) attached to each side of the frame. Two of them are vertically placed at the top of the specimen and 4 at the side walls in the horizontal direction (Figure 5). The entire system rests on the digital balance.

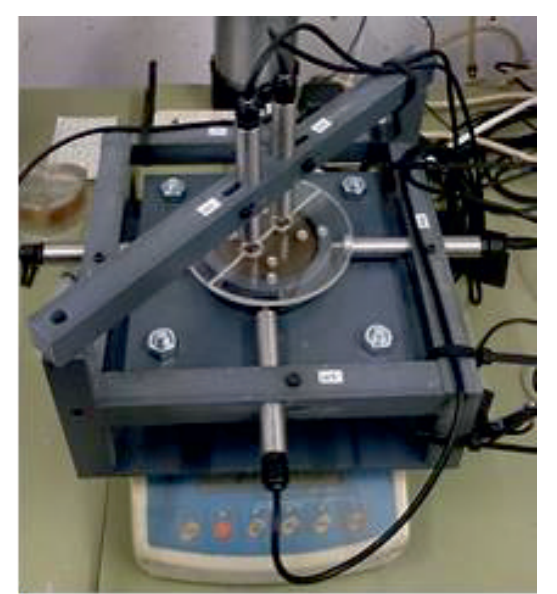

Figure 5. The laboratory set up for SWRC determination applying continuous hydraulic path changes (with tensiometer attached at the bottom).

The system is also equipped with a portable, split cover to avoid too rapid evaporation or drying of a sample during the measurement. The sample preparation procedure is the same as the one proposed for stage approach, however, the diameter was larger $(20 / 75 \mathrm{~mm})$. When the hydraulic path followed is drying the sample is simply left on the pedestal and enclosed within the split 
cover. When the procedure is reversed for the wetting path, water drops are applied by using a syringe through holes drilled in the Perspex cover, as shown on Figure 5.

\section{Results and discussion}

\subsection{Comparison of SWRC testing methods}

The results presented in the paper focus on determination and evaluation of SWRC obtained by the pressure plate system (applying axis translation technique) and direct suction measurement by using high suction probe. The results are plotted as a function of gravimetric water content (commonly used by engineers) and suction (Figure 6), but also the SWRCs are presented in terms of changes in volumetric water content (Figure 7) and degree of saturation (Figure 8). This is to give a wider picture of the hydraulic behaviour of the tested sandy clay material.

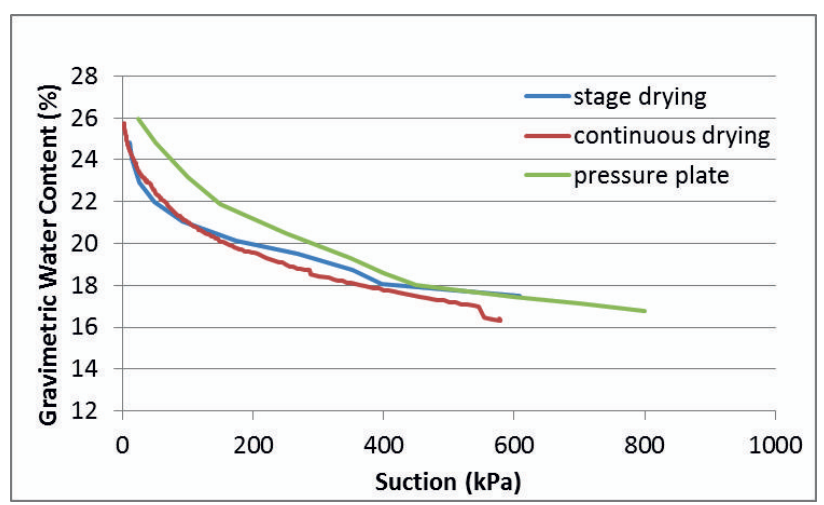

Figure 6. SWRC for different testing methods used, presented as gravimetric water content against suction.

From the graph (Figure 6) it can be seen that the suction measurements for the stage and continuous drying match each other, especially at the initial stage. The line inclination for the continuous approach is more consistent, which could be the effect of simultaneous reading of mass losses with suction increase. The readings could also be influenced by the differences in sample dimensions. The second graph (Figure 7) presents SWRC as a function of volumetric water content.

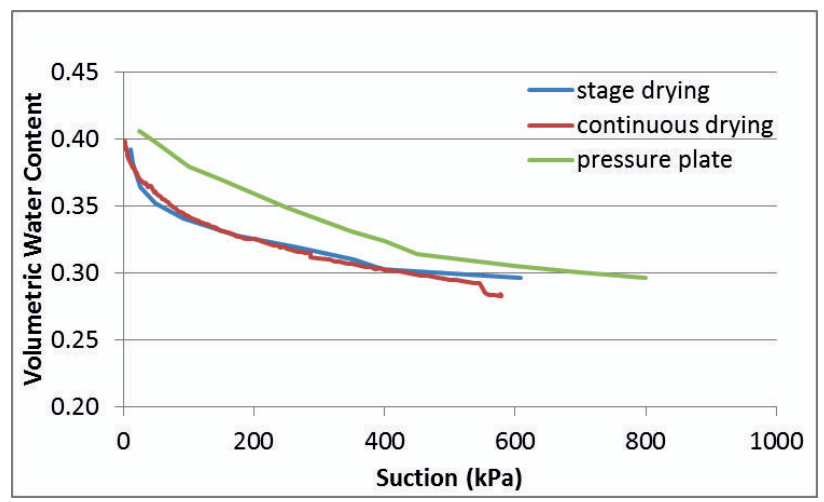

Figure 7. SWRC for different testing methods used, presented as volumetric water content against suction.

When calculating the volumetric water content, the changes in density of the sample is taken into account,
From this graph it can be noticed that the stage and continuous approach shows even better agreement, confirming the correctness of the results obtained. The third plot (Figure 8) presents the relationship between suction and degree of saturation ( $\mathrm{Sr})$.

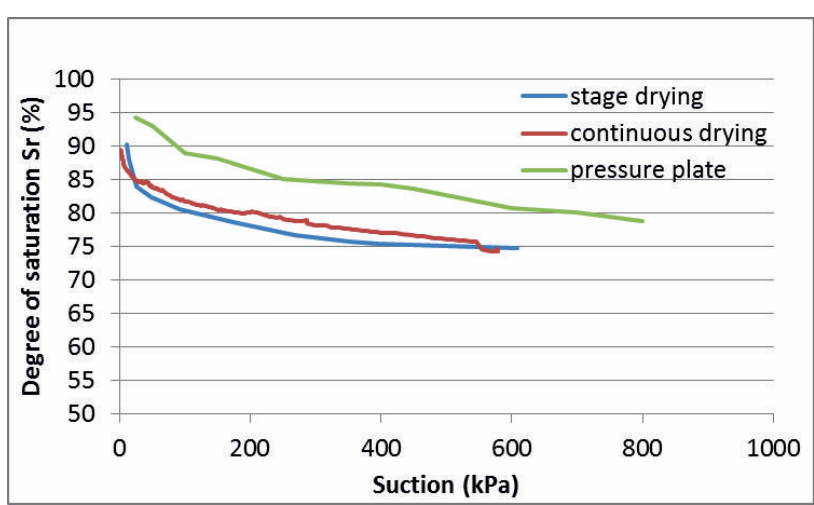

Figure 8. SWRC for different testing methods used, presented as degree of saturation against suction.

As for the previous figures there is again a quite good alignment for suction probe measurements (stage and continuous drying). However, it can be seen that the pressure plate test specimen started from a higher initial degree of saturation ( $94 \%$ rather than $90 \%$ ).

There is one main conclusion deriving from those results. It is clear that the pressure plate results plot above the lines recorded for tensiometer readings. An explanation put forward by Toll et al. [18] was that cavitation was prevented in the pressure plate tests (using axis translation) whereas cavitation could take place during natural drying. However, Toll et al. [19] has shown that this discrepancy is due to different volumetric paths followed in each test.

\subsection{Continuous hydraulic paths for silty clay}

The next stage of the research was to investigate how the soil will respond when subjected to repeated continuous wetting and drying cycles (Figure 9).

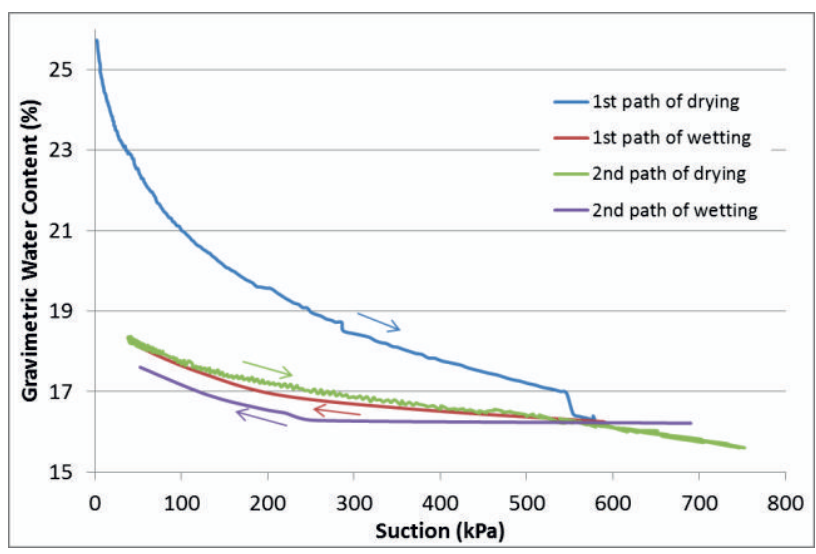

Figure 9. SWRCs for repeated drying and wetting cycles for sandy clay, using tensiometer measurements (continuous approach).

For that purpose the sample was prepared and subjected to drying as described earlier. When a certain value of suction was achieved then a continuous wetting 
path was commenced. The specimen was subjected to four hydraulic paths as presented on Figure 9. The graph shows that for each full cycle (drying and wetting) the hysteretic behaviour is quite different. For the first cycle the difference between the primary drying curve and the scanning (wetting) curve is much larger than for the second one. It shows that the three last paths lie very close to each other. Another practical observation was that the continuous approach was much less time consuming than the stage approach and the pressure plate method. A single path could be accomplished in 2 days whereas for pressure plate method it could be weeks.

\section{Conclusions and remarks}

The present study describes techniques allowing precise and reliable suction measurements. Two methods were compared and discussed. The pressure plate method which employs axis translation technique can be successfully used, however it is seen that this shows differences to the tensiometer method.

It was confirmed that the continuous tensiometer approach is a very efficient and effective method of measuring the water retention behaviour. It shows good agreement with the stage approach which could take 10 times longer to finish the complete test.

Another important conclusion deriving from the study is that the wetting and drying history have a significant impact on the hydraulic behaviour of tested material. It is a common knowledge that the wetting and drying paths for soil are not reversible. However, it is shown that the major differences occur in the first cycle and smaller differences are seen in subsequent scanning curve paths.

\section{Acknowledgments}

The authors would like to acknowledge EU COST Action TU1202 "Impact of climate change on engineered slopes for infrastructure" and iSMART project "Infrastructure slopes sustainable management and resilience assessment" (EPSRC EP/K027050/1), for the financial support of the study. The work described was carried out in the Unsaturated Soil laboratory at Durham University.

\section{References}

1. P.N. Hughes, S. Glendinning, J. Mendes, G. Parkin, D.G. Toll, D. Gallipoli, P. Miller. 2009. Full-scale testing to assess climate effects on embankments. Special Issue of Engineering Sustainability: Proc. Ins. of C. Eng, 162, 2, 67-79 (2009)

2. S. Au. Rain-Induced Slope Instability in Hong Kong, Eng. Geo, 51, 1, 1-36 (1998)

3. P. Osinski, R.J. Rickson, M.J. Hann, E. Koda. Assessment of slope stability influenced by vegetation cover and additional loads applied. Ann. Warsaw Univ. of Life Sci. - SGGW, Land Reclam. 46, 2, 81-91 (2014)
4. S.D.N. Lourenço. Suction Measurements and Water Retention in Unsaturated Soils, PhD Thesis, Durham University (2008)

5. D.G. Fredlund, H. Rahardjo. Soil mechanics for unsaturated soils. New York: Wiley (1993)

6. J. Mendes. Assessment of the impact of climate change on an instrumented embankment: an unsaturated soil mechanics approach. PhD Thesis, Durham University (2011)

7. D.G. Fredlund. Use of the soil-water characteristic curve in the implementation of unsaturated soil mechanics. Proc. Third Int. Conf. on Unsaturated Soils, UNSAT 2002, Recife, Brazil. 3 (2002)

8. D.G. Toll, M.S. Rahim, M. Karthikeyan, I. Tsaparas. Soil atmosphere interactions for analysing slopes in tropical soils, Proc. $14^{\text {th }}$ Int. Conf. IACMAG, Kyoto Japan (eds. F. Oka, A. Murakami, R. Uzuoka), London: Taylor \& Francis, 1333-1338 (2014)

9. S.J. Wheeler, R.J. Sharma, M.S.R Buisson. Coupling of hydraulic hysteresis and stress-strain behaviour in unsaturated soils. Geotechnique 53, 1, 41-54 (2003)

10. E. Koda, P. Osiński. Assessment of bio-mechanical reinforcement materials influencing slope stability, based on numerical analyses. Proc. of the $18^{\text {th }}$ Int. Conf. on Soil Mech. and Geotech. Eng. Press des Pontes, Paris. 3, 2525-2528 (2013)

11. Z. Skutnik, M. Biliniak. Suction controlled triaxial testing of unsaturated medium sand and sandy clay. Ann. Warsaw Univ. of Life Sci. - SGGW, Land Reclam. 46, 4, 301-307 (2014).

12. P.N. Hughes, S. Glendinning, D.G. Toll. Report on the design and construction of the BIONICS embankment. University of Newcastle upon Tyne Durham University (2005)

13. British Standard Institute, BS 1377: Methods of test for Soils of civil engineering purposes. Part 1-4, BSI, Milton Keynes (1990)

14. D.G. Toll. A data acquisition and control system for geotechnical testing, in Computing Developments in Civil and Structural Engineering (eds. B. Kumar and B.H.V. Topping), Edinburgh: Civil-Comp Press, 237-242 (1999)

15. S.D.N. Lourenço, D. Gallipoli, D.G. Toll, C.E. Augarde, F.A. Evans. A new procedure for the determination of the Soil Water Retention Curves by continuous drying using high suction tensiometers. Can. Geo. J., 48, 2, 327-335 (2011)

16. A.M. Ridley, J.B. Burland. A new instrument for the measurement of soil moisture suction. Geotechnique 43, 2, 321-324 (1993)

17. A. Tarantino, L. Mongiovì. Calibration of tensiometer for direct measurement of matric suction Geotechnique, 53, 1, 137-141 (2003)

18. D.G. Toll, S.D.N. Lourenço, J. Mendes. Advances in suction measurements using high suction tensiometers, Eng. Geo, 165, 29-37 (2013)

19. D.G. Toll, J.D. Asquith, A. Fraser, A.A. Hassan, G. Liu, S.D.N. Lourenço, J. Mendes, T. Noguchi, P. Osinski, R.A. Stirling, Tensiometer techniques for determining soil water retention curves. Proc. $6^{\text {th }}$ Asia-Pacific Conference on Unsaturated Soil. Guilin, China. London: Taylor \& Francis (2015). 